\title{
Low superior vena cava flow and intraventricular haemorrhage in preterm infants
}

\author{
Martin Kluckow, Nick Evans
}

\begin{abstract}
Objectives-To document the incidence, timing, degree, and associations of systemic hypoperfusion in the preterm infant and to explore the temporal relation between low systemic blood flow and the development of intraventricular haemorrhage (IVH).

Study design-126 babies born before 30 weeks' gestation (mean 27 weeks, mean body weight $991 \mathrm{~g}$ ) were studied with Doppler echocardiography and cerebral ultrasound at 5, 12, 24, and 48 hours of age. Superior vena cava (SVC) flow was assessed by Doppler echocardiography as the primary measure of systemic blood flow returning from the upper body and brain. Other measures included colour Doppler diameters of ductal and atrial shunts, as well as Doppler assessment of shunt direction and velocity, and right and left ventricular outputs. Upper body vascular resistance was calculated from mean blood pressure and SVC flow.
\end{abstract}

Results-SVC flow below the range recorded in well preterm babies was common in the first 24 hours (48 (38\%) babies), becoming significantly less common by 48 hours (6 (5\%) babies). These low flows were significantly associated with lower gestation, higher upper body vascular resistance, larger diameter ductal shunts, and higher mean airway pressure. Babies whose mothers had received antihypertensives had significantly higher SVC flow during the first 24 hours. Early IVH was already present in 9 babies at 5 hours of age. Normal SVC flows were seen in these babies except in 3 with IVH, which later extended, who all had SVC flow below the normal range at 5 and/or 12 hours. Eight of these 9 babies were delivered vaginally. Late IVH developed in 18 babies. 13 of 14 babies with grade 2 to 4 IVH had SVC flow below the normal range before development of an IVH. Two of 4 babies with grade 1 IVH also had SVC flow below the normal range before developing IVH, and the other 2 had SVC flow in the low normal range. In all, IVH was first seen after the SVC flow had improved, and the grade of IVH related significantly to the severity and duration of low SVC flow. The 9 babies who had SVC flow below the normal range and did not develop IVH or periventricular leucomalacia were considerably more mature (median gestation 28 $v 25$ weeks).
Conclusions-Low SVC flow may result from an immature myocardium struggling to adapt to increased extrauterine vascular resistances. Critically low flow occurs when this is compounded by high mean airway pressure and large ductal shunts out of the systemic circulation. Late IVH is strongly associated with these low flow states and occurs as perfusion improves.

(Arch Dis Child Fetal Neonatal Ed 2000;82:F188-F194)

Keywords: very preterm infants; blood flow; cerebral haemorrhage; superior vena cava

In the beagle puppy model, intraventricular haemorrhage (IVH) is produced by inducing a severe hypoperfusion-reperfusion cycle. ${ }^{1}$ Our observations of early cardiovascular haemodynamics suggested that IVH in human preterm infants may relate to a similar cycle. ${ }^{23}$ Low ventricular outputs are common on day 1 in very preterm babies, subsequently improve, and are unusual after day $2 .^{2}$ This hypoperfusion-reperfusion cycle happens in the time frame in which most IVHs occur. Babies who developed severe IVH had significantly lower early right ventricular outputs, ${ }^{3}$ which in turn were associated with left to right shunts through larger diameter patent ductus arteriosus and higher mean airway pressures. ${ }^{2}$

We hypothesised that IVH relates to a systemic and cerebral hypoperfusionreperfusion cycle resulting from slow postnatal adaptation of the immature cardiovascular system. The aims of this study were twofold: firstly, to document the incidence, timing, degree, and possible causes of systemic hypoperfusion in the preterm infant, and, secondly, to explore any temporal relation between low systemic blood flow and the development of IVH. Because blood pressure correlates only weakly with systemic blood flow ${ }^{4}$ and because intracardiac shunts in the adapting heart confound the interpretation of ventricular outputs, ${ }^{56}$ measurement of superior vena cava (SVC) flow is used in this study as a novel measure of upper body systemic blood flow. ${ }^{7}$ About $80 \%$ of upper body blood flow goes to the brain, ${ }^{8}$ so this may provide a useful marker of cerebral perfusion.

\section{Methods}

STUDY POPULATION

The entry criteria for this study were preterm birth before 30 weeks' gestation and informed parental consent. The 126 babies enrolled during the 20 month time period of the study represented $85 \%$ of eligible babies. Parental 
consent was refused for five babies, and 19 eligible babies were not studied, as neither investigator was available when they were born. The 126 babies studied had a mean gestation of 27 weeks (range 23-29) and a mean birth weight of $991 \mathrm{~g}$ (range 420-1630). Just over half (52\%) were boys, $87 \%$ had received antenatal steroids, and $91 \%$ were inborn. Some $76 \%$ were ventilated for more than one day, and $79 \%$ of these ventilated babies were treated with early rescue surfactant (Survanta; Abbott Australasia Ltd, Sydney, Australia). High frequency oscillatory ventilation was not used. The respiratory diagnosis was hyaline membrane disease in $60 \%$, pulmonary immaturity in $15 \%$, pneumonia in $3 \%$, pulmonary hypoplasia in $0.8 \%$ (one baby), and $20 \%$ had normal lungs. Twenty three $(18 \%)$ of the babies died in the neonatal period. Seven who died from respiratory failure on days 1 and 2 are excluded from any analysis in which IVH is the major outcome. Of the 16 other babies who died, 10 had intensive care withdrawn as a result of a severe IVH, five died from late sepsis, and one died late from respiratory failure. The Royal Prince Alfred Hospital ethics committee approved the study, and babies were studied with informed written consent from their parents.

ULTRASOUND STUDIES

All infants had serial ultrasound examinations, which included an echocardiogram and a cerebral ultrasound, as close as possible to 5, 12, 24, and 48 hours after birth. The first ultrasound examination was performed after stabilisation was complete and the first dose of surfactant, if indicated, had been given.

\section{Echocardiographic data collection}

This was performed with an Acuson 128/XP10 ultrasound scanner with a $5 \mathrm{MHz}$ or a $7 \mathrm{MHz}$ transducer incorporating colour flow, pulsed wave, and continuous wave Doppler. The scan was recorded on to videotape and later measured from the videotape. Structural normality of the heart was established on the initial scan. At each study, the following measures were taken using protocols that have been described previously in detail ${ }^{4-6}$ :

(a) Doppler volumetric measurement of right and left ventricular output;

(b) colour Doppler diameter of ductus arteriosus shunt (a semiquantitative measure of shunt size ${ }^{6}$ ) and pulsed or continuous wave Doppler assessment of shunt direction and velocity;

(c) colour Doppler diameter of interatrial shunt (a semiquantitative measure of shunt size $^{5}$ ) and pulsed or continuous wave Doppler assessment of shunt direction and velocity;

(d) SVC flow, measured using the method described in the previous paper. ${ }^{7}$

Cerebral ultrasound

This was performed with a $7 \mathrm{MHz}$ transducer, and any IVH was noted and classified according to Papile grading. Further routine head ultrasounds were performed between day 4 and 7 and on day 28.

HAEMODYNAMIC MANAGEMENT

Attending clinicians were not informed of the findings unless there was a specific clinical concern, such as a clinical suspicion of a patent ductus arteriosus or hypotension unresponsive to treatment. The blood pressure support protocol aimed to keep the mean blood pressure above the infant's gestation in weeks ${ }^{9}$ using volume expansion $(10 \mathrm{ml} / \mathrm{kg})$ followed by dobutamine $(10-20 \mu \mathrm{g} / \mathrm{kg} / \mathrm{min})$ depending on response. If the blood pressure remained low, dopamine at doses up to $10 \mu \mathrm{g} / \mathrm{kg} / \mathrm{min}$ was used. In all, $36 \%$ of babies received inotropes during the first 48 postnatal hours. The aim of this study was to examine overall changes in flow, and the response to inotropic support was not specifically investigated. Indometacin was used to treat symptomatic patent ductus arteriosus confirmed to be haemodynamically significant on echocardiography. Thirty five of the cohort received indometacin, with the first dose given at a median time of 48 hours (range 12-365 hours).

\section{Clinical and physiological data}

Oxygen requirements, ventilatory settings, and intra-arterial blood pressures were recorded at the time of each scan. All arterial blood gases with ventilatory settings at the time were recorded. In 106 babies (84\%), physiological data including blood pressure, heart rate, oxygen saturation, and transcutaneous oxygen and carbon dioxide were downloaded every five minutes from the Hewlett-Packard Merlin monitors to a central database (Docvue; Hewlett-Packard, Andover, Massachusetts, USA) for the first 60 hours of admission. This was not possible for technical reasons in the other 20 babies in whom hourly recordings of these data were taken from the nursing charts.

Upper body vascular resistance (UBVR)

This was calculated as mean arterial blood pressure at the time of the scan divided by SVC flow ( $\mathrm{mm} \mathrm{Hg}$ per $\mathrm{ml} / \mathrm{kg} / \mathrm{min}$ ).

\section{STATISTICAL ANALYSIS}

Data were analysed with a PC based statistics package (SPSS for Windows) using $\chi^{2}$ test, Kruskall-Wallis analysis of variance, MannWhitney $U$ test, and multilinear regression. $p<0.05$ was accepted as significant except for multiple univariant comparisons, for which a Bonferoni correction to $<0.01$ was applied.

\section{Results}

NORMAL SVC FLOW

As previously described, ${ }^{7}$ a normal range for SVC flow was derived from 25 of the 126 preterm babies who had radiologically normal lungs with minimal requirements for ventilatory support. The normal range was defined as being above the lowest recorded SVC flow at each of the four scans-that is, above 30, 34, 42 , and $46 \mathrm{ml} / \mathrm{kg} / \mathrm{min}$ respectively at $5,12,24$, and 48 hours of age. 
Table 1 Comparison of haemodynamic and respiratory variables at each of the four scans between babies with low and those with normal superior vena cava (SVC) flow

\begin{tabular}{|c|c|c|c|c|c|c|c|c|c|c|c|c|}
\hline & \multicolumn{3}{|l|}{5 hour study } & \multicolumn{3}{|c|}{12 hour study } & \multicolumn{3}{|c|}{24 hour study } & \multicolumn{3}{|c|}{48 hour study } \\
\hline & $\begin{array}{l}\text { Low flow } \\
(n=19)\end{array}$ & $\begin{array}{l}\text { Normal flow } \\
(n=105)\end{array}$ & p Value & $\begin{array}{l}\text { Low flow } \\
(n=22)\end{array}$ & $\begin{array}{l}\text { Normal flow } \\
(n=100)\end{array}$ & $p$ Value & $\begin{array}{l}\text { Low flow } \\
(n=17)\end{array}$ & $\begin{array}{l}\text { Normal flow } \\
(n=101)\end{array}$ & $p$ Value & $\begin{array}{l}\text { Low flow } \\
(n=6)\end{array}$ & $\begin{array}{l}\text { Normal flow } \\
(n=109)\end{array}$ & $p$ Value \\
\hline Age at scan (hours) & $5.0(1.0)$ & $5.0(1.5)$ & 0.5 & $12.8(2.3)$ & $12.9(2.4)$ & 0.9 & $24(1.1)$ & $24(2.0)$ & 0.87 & $49(3)$ & $48(3)$ & 0.44 \\
\hline $\begin{array}{l}\text { SVC flow } \\
\qquad(\mathrm{ml} / \mathrm{kg} / \mathrm{min})\end{array}$ & $\begin{array}{l}23 \\
(10-29)\end{array}$ & $\begin{array}{l}55 \\
(31-143)\end{array}$ & & $\begin{array}{l}27 \\
(16-34)\end{array}$ & $\begin{array}{l}63 \\
(34-134)\end{array}$ & & $\begin{array}{l}30 \\
(10-42)\end{array}$ & $\begin{array}{l}73 \\
(42-150)\end{array}$ & & $\begin{array}{l}42 \\
(17-46)\end{array}$ & $\begin{array}{l}82 \\
(47-158)\end{array}$ & \\
\hline $\begin{array}{l}\text { SVC velocity time } \\
\text { integral }(\mathrm{mm} / \mathrm{s})\end{array}$ & $\begin{array}{l}55 \\
(24-98)\end{array}$ & $\begin{array}{l}79 \\
(31-98)\end{array}$ & & $\begin{array}{l}61 \\
(33-88)\end{array}$ & $\begin{array}{l}81 \\
(40-160)\end{array}$ & & $\begin{array}{l}62 \\
(39-105)\end{array}$ & $\begin{array}{l}94 \\
(42-176)\end{array}$ & & $\begin{array}{l}51 \\
(27-90)\end{array}$ & $\begin{array}{l}100 \\
(48-226)\end{array}$ & \\
\hline $\begin{array}{l}\text { Mean SVC diameter } \\
(\mathrm{mm})\end{array}$ & $\begin{array}{l}2.0 \\
(1.3-3.1)\end{array}$ & $\begin{array}{l}2.55 \\
(1.6-4.1)\end{array}$ & & $\begin{array}{l}1.8 \\
(1.05-2.4)\end{array}$ & $\begin{array}{l}2.6 \\
(1.7-3.7)\end{array}$ & & $\begin{array}{l}1.85 \\
(1.4-2.5)\end{array}$ & $\begin{array}{l}2.65 \\
(1.8-3.8)\end{array}$ & & $\begin{array}{l}2.1 \\
(1.7-2.7)\end{array}$ & $\begin{array}{l}2.7 \\
(1.5-3.7)\end{array}$ & \\
\hline $\begin{array}{l}\text { Ductal diameter } \\
(\mathrm{mm})\end{array}$ & $\begin{array}{l}2.1 \\
(0.9-3)\end{array}$ & $\begin{array}{l}1.6 \\
(0-3.5)\end{array}$ & 0.0007 & $\begin{array}{l}1.35 \\
(0-2.8)\end{array}$ & $\begin{array}{l}1.1 \\
(0-2.8)\end{array}$ & 0.08 & $\begin{array}{l}0.9 \\
(0-2.2)\end{array}$ & $\begin{array}{l}0.8 \\
(0-3.1)\end{array}$ & 0.65 & $\begin{array}{l}0 \\
(0-2)\end{array}$ & $\begin{array}{l}0.4 \\
(0-3)\end{array}$ & 0.5 \\
\hline Heart rate & $\begin{array}{l}142 \\
(125-192)\end{array}$ & $\begin{array}{l}144 \\
(121-181)\end{array}$ & 0.9 & $\begin{array}{l}148 \\
(130-170)\end{array}$ & $\begin{array}{l}144 \\
(80-179)\end{array}$ & 0.28 & $\begin{array}{l}144 \\
(129-163)\end{array}$ & $\begin{array}{l}144 \\
(107-188)\end{array}$ & 0.8 & $\begin{array}{l}159 \\
(153-170)\end{array}$ & $\begin{array}{l}148 \\
(121-192)\end{array}$ & 0.03 \\
\hline $\mathrm{PCO}_{2}$ & $\begin{array}{l}38 \\
(21-65)\end{array}$ & $\begin{array}{l}37.5 \\
(18-62)\end{array}$ & 0.9 & $\begin{array}{l}35 \\
(28-68)\end{array}$ & $\begin{array}{l}36.4 \\
(23-64)\end{array}$ & 0.98 & $\begin{array}{l}34 \\
(27-46)\end{array}$ & $\begin{array}{l}38 \\
(27-67)\end{array}$ & 0.008 & $\begin{array}{l}40 \\
(33-51)\end{array}$ & $\begin{array}{l}43 \\
(31-64)\end{array}$ & 0.6 \\
\hline $\mathrm{FiO}_{2}$ & $\begin{array}{l}0.28 \\
(0.21-1)\end{array}$ & $\begin{array}{l}0.25 \\
(0.21-1)\end{array}$ & 0.9 & $\begin{array}{l}0.3 \\
(0.21-0.5)\end{array}$ & $\begin{array}{l}0.25 \\
(0.21-0.9)\end{array}$ & 0.18 & $\begin{array}{l}0.25 \\
(0.21-1)\end{array}$ & $\begin{array}{l}0.24 \\
(0.21-0.7)\end{array}$ & 0.13 & $\begin{array}{l}0.22 \\
(0.21-0.3)\end{array}$ & $\begin{array}{l}0.24 \\
(0.21-1)\end{array}$ & 0.44 \\
\hline $\begin{array}{l}\text { Mean airway } \\
\text { pressure }\left(\mathrm{cm} \mathrm{H}_{2} \mathrm{O}\right)\end{array}$ & $\begin{array}{l}11 \\
(8-19)\end{array}$ & $\begin{array}{l}9.4 \\
(0-21)\end{array}$ & 0.005 & $\begin{array}{l}9.25 \\
(6-13)\end{array}$ & $\begin{array}{l}7.8 \\
(0-13)\end{array}$ & 0.01 & $8.6(6-11)$ & $\begin{array}{l}7.3 \\
(0-14)\end{array}$ & 0.02 & $\begin{array}{l}8.1 \\
(6-10.5)\end{array}$ & $\begin{array}{l}7.7 \\
(0-19)\end{array}$ & 0.8 \\
\hline $\begin{array}{l}\text { Mean blood pressure } \\
(\mathrm{mm} \mathrm{Hg})\end{array}$ & $\begin{array}{l}29 \\
(20-39)\end{array}$ & $\begin{array}{l}31 \\
(15-46)\end{array}$ & 0.19 & $\begin{array}{l}33 \\
(22-47)\end{array}$ & $\begin{array}{l}33 \\
(20-51)\end{array}$ & 0.57 & $\begin{array}{l}35 \\
(23-42)\end{array}$ & $\begin{array}{l}36 \\
(23-50)\end{array}$ & 0.5 & $\begin{array}{l}39 \\
(30-42)\end{array}$ & $\begin{array}{l}38 \\
(24-54)\end{array}$ & 0.7 \\
\hline Vascular resistance & $\begin{array}{l}1.2 \\
(0.9-3.1)\end{array}$ & $\begin{array}{l}0.54 \\
(0.2-1)\end{array}$ & 0.0001 & $\begin{array}{l}1.15 \\
(0.8-4.5)\end{array}$ & $\begin{array}{l}0.53 \\
(0.2-1)\end{array}$ & 0.0001 & $\begin{array}{l}1.13 \\
(0.7-2.9)\end{array}$ & $\begin{array}{l}0.5 \\
(0.26-1.0)\end{array}$ & 0.0001 & $\begin{array}{l}0.99 \\
(0.87-2.0)\end{array}$ & $\begin{array}{l}0.46 \\
(0.2-0.98)\end{array}$ & 0.0002 \\
\hline$\%$ on dopamine & 0 & 0 & & 13 & 3 & 0.07 & 18 & 2 & .02 & 0 & 2 & 0.12 \\
\hline$\%$ on dobutamine & 0 & 0 & & 36 & 24 & 0.35 & 64 & 26 & .002 & 50 & 12 & 0.03 \\
\hline
\end{tabular}

Figures are given as median and range with the exception of age at scan, which is mean (SD).

Because SVC flow was the basis of the groupings, $p$ values are not given for SVC parameters.

LOW SVC FLOW

In the whole cohort of 126 babies, median SVC flow rose from $57 \mathrm{ml} / \mathrm{kg} / \mathrm{min}$ (range 10-143) at 5 hours, to $59 \mathrm{ml} / \mathrm{kg} / \mathrm{min}(16-133)$ at 12 hours, to $69 \mathrm{ml} / \mathrm{kg} / \mathrm{min}(10-150)$ at 24 hours, and to $82 \mathrm{ml} / \mathrm{kg} / \mathrm{min}(17-158)$ at 48 hours. The increases between the 12 and 24 hour measurements and the 24 and 48 hour measurements were significant $(p<0.0001)$. SVC flow below the normal range was measured in $15 \%$ of babies at 5 hours, $18 \%$ at 12 hours, and $14 \%$ at 24 hours; $38 \%$ of all babies had at least one measure below the normal range during the first 24 hours. Some $80 \%$ of babies had their lowest measure of SVC flow at 5 or 12 hours. Low SVC flow was significantly less common by 48 hours $(5 \%, \mathrm{p}<0.02)$.

ANTENATAL AND DEMOGRAPHIC ASSOCIATIONS WITH LOW SVC FLOW

Antenatal and demographic factors (including gestation, birthweight percentile, antenatal steroids, maternal antihypertensive treatment, and Apgar at 5 minutes) were analysed against the mean SVC flow calculated from the three measurements in the first 24 hours. There was a significant correlation between 24 hour averaged SVC flow and gestation $(r=0.45, \mathrm{p}<0.0001)$, but no relation with the Apgar score, birthweight percentile, or use of antenatal steroids. Median 24 hour averaged SVC flow was significantly higher in the 31 babies whose mothers had received antihypertensives (71 (range 22-104) v $59(14-131) \mathrm{ml} / \mathrm{kg} / \mathrm{min} ; \mathrm{p}=0.004)$.

CARDIORESPIRATORY ASSOCIATIONS WITH LOW SVC FLOW

For each of the four scans, the following were compared between babies with low and normal flow: echocardiographic variables (including colour Doppler diameter of the ductal and atrial shunt), respiratory variables (including oxygen requirement and mean airway pressure at the time of the scan, and mean $\mathrm{PCO}_{2}$ in the six hours preceding the scan), and haemodynamic measures (including heart rate, mean blood pressure, and calculated UBVR at the time of the scan).

At the 5 hour scan, the 19 babies with low SVC flow had significantly larger diameter patent ductus arteriosus, higher mean airway pressure, and higher calculated UBVR (table 1). At the 12 hour scan, the 22 babies with low SVC flow had significantly higher mean airway pressure and higher calculated UBVR. At the 24 hour scan, the 17 babies with low SVC flow had significantly larger diameter atrial shunts, lower $\mathrm{PCO}_{2}$ in the preceding six hours, more were receiving dobutamine, and they had higher UBVR. At the 48 hour scan, the six babies with low SVC flow had significantly higher UBVR. The associations at the 5 and 12 hour scan remained significant after controlling for gestation and maternal antihypertensives with multivariate analysis, but at 24 and 48 hours, only higher UBVR remained significantly associated with low SVC flow.

Not all babies with large diameter ducts had low SVC flow (table 1). The above analysis was repeated for the 5 hour scan on the subgroup of babies with ductal diameters above the cohort

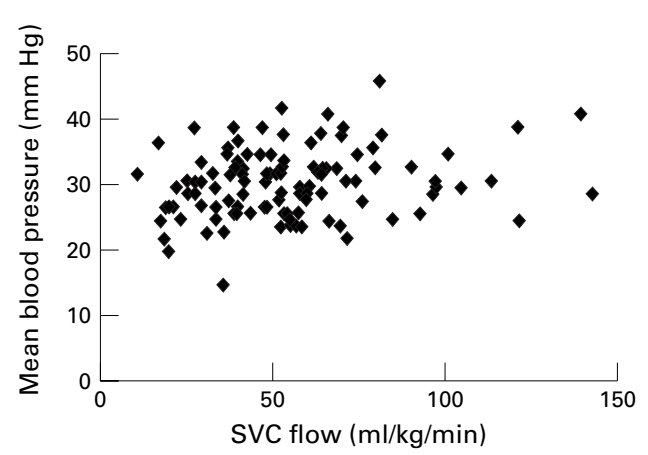

Figure 1 Relation between mean blood pressure and superior vena cava $(S V C)$ flow $(r=0.21, p=0.023)$ at the 5 hour scan. 


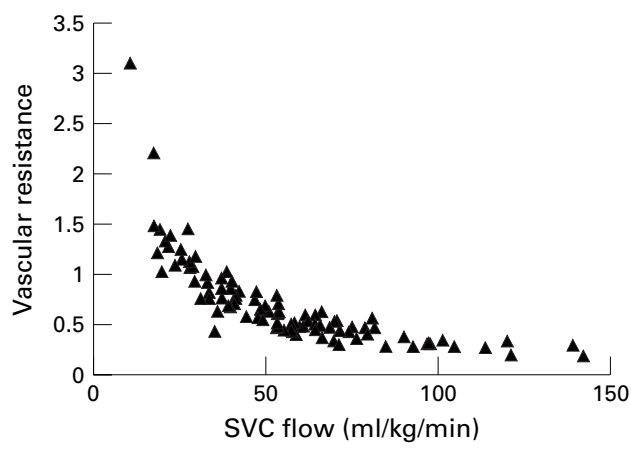

Figure 2 Inverse relation between vascular resistance and superior vena cava $(S V C)$ flow $(r=0.94, p<0.0001)$ at the 5 hour scan.

median $(1.6 \mathrm{~mm})$. The babies with low SVC flow had significantly higher UBVR (1.2 v $0.6 \mathrm{~mm} \mathrm{Hg}$ per $\mathrm{ml} / \mathrm{kg} / \mathrm{min}$; $\mathrm{p}<0.0001)$, but there were no differences in the other variables.

The limitations of blood pressure as a marker of systemic blood flow are emphasised by the weak relation at all scans between SVC flow and mean blood pressure $(r<0.25)$ (fig $1)$. This relation was just significant for the first three scans $(\mathrm{p}<0.04)$ but not at 48 hours $(\mathrm{p}=0.45)$. This weak relation signified a very close inverse relation between SVC flow and UBVR at all scans $(r>0.94, \mathrm{p}<0.0001$; fig $2)$, with exponentially increasing UBVR at lower SVC flows. At no time was the heart rate significantly associated with low SVC flow.

\section{SVC FLOW AND IVH}

Early IVH

In nine babies, an IVH was already present on the 5 hour scan (early IVH group). Of this group, one baby had a grade $4 \mathrm{IVH}$, one had a grade 2 which extended to a grade 3 , and seven had a grade 1 IVH, two of which extended to grade 2 . In the six babies in whom the early IVH did not extend, all SVC flows were in the normal range at the 5 hour scan and remained normal thereafter (fig 3). But in all three babies in which the IVH extended after the 5 hour scan, SVC flow was below the normal range at the 5 or 12 hour scan (fig 3).

There was a significantly higher rate of vaginal delivery for these nine babies than for the rest of the cohort $(89 \% v 34 \% ; \mathrm{p}=0.002)$. However, their early clinical course was no dif-

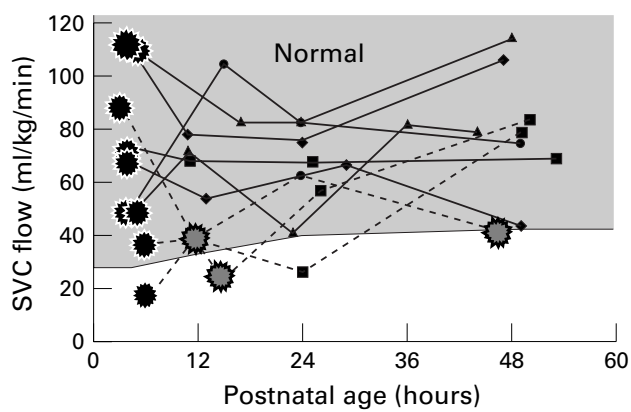

Figure 3 Individual change in superior vena cava (SVC) flow in nine babies with early intraventricular haemorrhage (IVH). The black stars represent the scan in which IVH was first seen. The dotted lines represent the babies in whom this early IVH extended. A grey star marks the scan in which extension was first seen. The shaded area represents the normal range found in uncomplicated preterm babies.

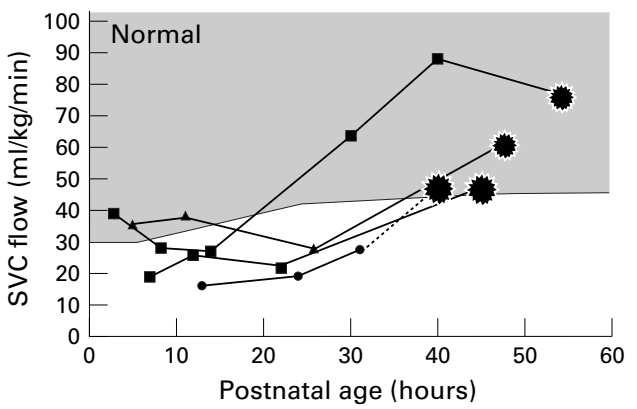

Figure 4 Individual change in superior vena cava (SVC) flow in four babies with late grade 3 intraventricular haemorrhage (IVH). The black stars represent the scan in which IVH was first seen. The shaded area represents the normal range found in uncomplicated preterm babies. The dotted line represents one baby who suddenly collapsed and died with a massive IVH for whom we have had to speculate what happened after the last scan.

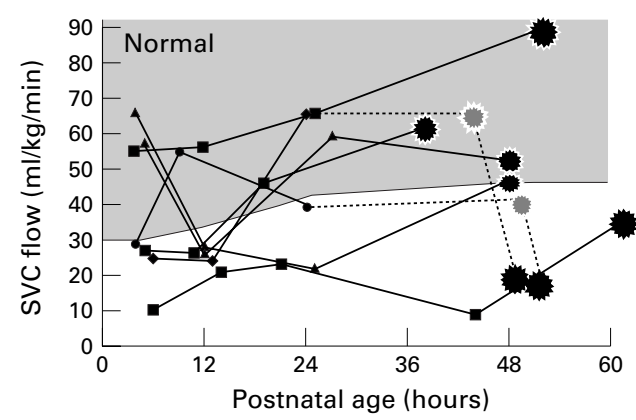

Figure 5 Individual change in superior vena cava (SVC) flow in seven babies with late grade 4 intraventricular haemorrhage (IVH). The black stars represent the scan in which IVH was first seen. The shaded area represents the normal range found in uncomplicated preterm babies. The dotted lines represent two babies who had just collapsed with an IVH and were hypovolaemic at their last scan. They were previously stable so we have speculated what happened before the last scan.

ferent from the rest of the cohort, as measured by cord arterial $\mathrm{pH}, 5$ minute Apgar, and mean oxygenation index over the first six postnatal hours.

\section{Late IVH}

Eighteen babies developed IVH after the initial ultrasound (late IVH group); $11 \%$ of these were first seen at the 12 hour scan, a further $22 \%$ at 24 hours, and the remaining $67 \%$ at 48 hours.

Fourteen were of grade 2 or more (three of grade 2 , four of grade 3 , seven of grade 4 ). In 13 of these 14 babies, SVC flows below the normal range (mean $23 \mathrm{ml} / \mathrm{kg} / \mathrm{min}$, range 10-29) were recorded before development of IVH. The one remaining baby, with a small unilateral grade $4 \mathrm{IVH}$, had SVC flows in the normal range (see fig 5). That baby had been born with a cord arterial base excess of -16 . Figures 4 and 5 show the individual changes in SVC flow in relation to when the IVH was first seen in the four babies with grade 3 IVH and the seven babies with grade 4 IVH respectively. Two of the four babies who had late grade 1 IVH also had SVC below the normal range before their IVH. The other two had SVC flow in the low normal range (34 and $39 \mathrm{ml} / \mathrm{kg}$ / min). In all babies, the late IVH was first seen after the SVC flow had improved. 
Table 2 Comparison of the minimum superior vena cava (SVC) flow and the number of recordings of SVC flow $<30 \mathrm{ml} / \mathrm{kg} / \mathrm{min}$ in babies with no intraventricular haemorrhage (IVH), grade 1/2 late IVH, and grade 3/4 late IVH

\begin{tabular}{lllll}
\hline & $\begin{array}{l}\text { No late IVH } \\
(n=92)\end{array}$ & $\begin{array}{l}\text { Late grade 1 or 2 } \\
\text { IVH }(n=7)\end{array}$ & $\begin{array}{l}\text { Late grade 3 or } 4 \\
\text { IVH }(n=11)\end{array}$ & p Value \\
\hline $\begin{array}{l}\text { Lowest SVC flow }(\mathrm{ml} / \mathrm{kg} / \mathrm{min}) \\
\text { Number of SVC flow recordings }\end{array}$ & $44(17-96)$ & $29(18-39)$ & $26(10-55)$ & 0.0001 \\
$<30 \mathrm{ml} / \mathrm{kg} / \mathrm{min}$ & $0(0-3)$ & $1(0-1)$ & $2(0-3)$ & 0.0001
\end{tabular}

Values are medians and range.

Early IVH and babies dying before IVH could be assessed as an outcome are excluded from this analysis

With increasing grade of IVH, the median minimum SVC flow was significantly lower $(p=0.0001)$ and the number of measurements below the normal range was significantly higher $(p=0.0001)$ (table 2$)$. Six of the 11 babies who developed grade 3 or 4 IVH showed serious acute respiratory deterioration (five had a pulmonary haemorrhage and one a pneumothorax) in the time period in which the IVH occurred.

LOW SVC FLOW IN OTHER BABIES

SVC flow below the normal range occurred in 11 babies who did not subsequently develop IVH. Two of these babies developed periventricular leucomalacia (PVL). To explore differences that may relate to the development of cerebral ultrasound changes, the 26 babies whose minimum SVC flow was $<30 \mathrm{ml} / \mathrm{kg} / \mathrm{min}$ were divided into three groups: no IVH $(n=9)$, PVL $(n=2)$, and late IVH $(n=15)$. The babies who did not develop head changes on ultrasound examination were significantly more mature than those who did, respectively 28 (24-29) weeks, 26.5 (26-27) weeks, and 25 $(24-28)$ weeks $(\mathrm{p}=0.015)$. There were no significant differences in other variables tested. An SVC flow below $30 \mathrm{ml} / \mathrm{kg} / \mathrm{min}$ predicted late cerebral ultrasound changes (late IVH, extending early IVH, or PVL) with $80 \%$ sensitivity and $90 \%$ specificity.

PERIVENTRICULAR LEUCOMALACIA

Four of the 126 babies developed multicystic PVL. As described above, very low SVC flow was recorded in two of these (minimum SVC flow 19.1 and $19.4 \mathrm{ml} / \mathrm{kg} / \mathrm{min}$ ); however, the other two had normal SVC flow throughout the study period (minimum SVC flow 44 and $50 \mathrm{ml} / \mathrm{kg} / \mathrm{min}$ ).

\section{Discussion}

These data have documented the incidence and extent of low systemic blood flow in the very preterm infant during the first 24 hours after birth, emphasising that these low flow states are poorly predicted by measurement of systemic blood pressure. Furthermore, we have shown a strong association between these observed low flow states and subsequent IVH as the flow improves.

This vulnerability to low flow decreases with postnatal age, so that by 48 hours it is rare. Why does this happen? As we have observed previously in relation to ventricular outputs, ${ }^{23}$ the diameter of the ductus arteriosus and the mean airway pressure were negatively associated with SVC flow, with the duct diameter being most significantly associated with low

\section{Key messages}

- Critically low superior vena cava flow occurs in a significant minority of very preterm infants

- These low flow states are poorly predicted by blood pressure

- This low flow is commonest in the first 12 to 24 hours, improving spontaneously after this time

- Late IVH is strongly associated with these low flow states and occurs as perfusion improves

SVC flow at the 5 hour scan. At this early time, $50 \%$ of the ducts had constricted to insignificant size $(<1.6 \mathrm{~mm})$, but the other $50 \%$ were haemodynamically significant. Even at this early stage, the predominant direction of ductal shunting is left to right, so larger ducts drain significant volumes of blood away from the systemic circulation. The negative association with mean airway pressure probably reflects the well documented negative influence of positive pressure ventilation on cardiac output. ${ }^{10-12}$ The individual impact both of large ducts and high mean airway pressure on SVC flow varied widely, with many babies maintaining their SVC flow in the presence of these negative influences. These babies were defined by lower systemic vascular resistance and increasing postnatal age. By 24 hours, neither ductal diameter nor mean airway pressure was significantly associated with low SVC flow, emphasising the early haemodynamic vulnerability.

This inconsistent effect of both large ducts and high mean airway pressure makes it likely that these are compounding factors rather than the fundamental cause of low systemic blood flow. Shorter gestation was significantly associated with low flow, and, although we did not measure myocardial function because of methodological problems in preterm babies, ${ }^{13}$ we speculate that this association relates to the limited contractile reserve of the immature myocardium. ${ }^{14}$ Specifically, the preterm myocardium has been shown to have a limited ability to respond to an increased afterload. ${ }^{15} 16$ During normal postnatal adaptation, there are large changes in ventricular workload in response to the change from low intrauterine vascular resistance to increased extrauterine resistance, ${ }^{17}{ }^{18}$ and these data have shown a very close inverse correlation between resistance and SVC flow. This could be a compensatory response, but such compensation is catecholamine driven and should also result in a raised heart rate, which we did not observe. Alternatively the combination of an immature myocardium and high vascular resistance may be the cause of these low flow states. The observation that maternal antihypertensive treatment was protective against low SVC flow may be due to their vasodilating properties offloading the adapting preterm heart. ${ }^{19} 20$

Some $80 \%$ of upper body blood flow goes to the brain, ${ }^{8}$ so when SVC flow is very low, it is likely that the cerebral blood flow is also low. 
Data on humans have pointed to early low cerebral flow being a risk factor for IVH, ${ }^{21}{ }^{22}$ and, in the animal model, it is a prerequisite for the occurrence of haemorrhage. ${ }^{123}$ The germinal matrix is uniquely vulnerable to ischaemic injury because of the watershed nature of the blood supply. ${ }^{24}$ Lou $^{25}$ recognised that an antecedent ischaemic insult to the germinal matrix capillaries, possibly occurring antenatally, was probably important in the pathogenesis of IVH. In our study, almost all the babies with late IVH had a postnatal period of low blood flow to the upper body preceding the IVH, with SVC flows around $30 \%$ of the average found in healthy preterm babies. Furthermore the worse the hypoperfusion, the more severe the IVH once flow had improved. Hypoperfusion was not seen in most of the babies with an early IVH, but we suggest that a similar cycle may be occurring but in a different time frame. Because the IVH had already occurred, we recorded only the reperfusion part of the cycle, with the hypoperfusion having occurred previously, possibly during labour and delivery. All except one of these babies were delivered by the vaginal route, a previously identified risk factor for early IVH. ${ }^{26}{ }^{27}$ Preterm babies may be less able than term babies to cope with the periods of hypoxia that occur during vaginal delivery.

The late IVHs were all first seen after SVC flow had improved. A pressure passive cerebral circulation resulting from a lack of cerebral autoregulation has been implicated in the pathogenesis of IVH. Recent data have suggested that this may be an acquired rather than a maturity related problem. ${ }^{22} 2829$ Our data would be consistent with this, in that IVH did not always occur immediately on reperfusion and, in keeping with the observations of Funato et al, ${ }^{30}$ over half the babies who had late grade 3 or $4 \mathrm{IVH}$ had a severe acute respiratory deterioration in the time period in which the IVH occurred. In fetal and neonatal lambs, an hypoxic insult quickly compromises autoregulation of the cerebral circulation. Impaired autoregulation in preterm babies may be a secondary problem that compounds the vulnerability of an ischaemically damaged germinal matrix endothelium to haemorrhagic rupture during reperfusion.

Individual response to an insult depends on vulnerability. The observation that babies with very low SVC flow who did not develop IVH or PVL were more mature mirrors the animal model. ${ }^{1}$ Logic would dictate that these low SVC flows must relate to the pathogenesis of PVL, but there were insufficient cases in this study to be able to draw any firm conclusions. Two babies with PVL had extremely low SVC flow ( $<20 \mathrm{ml} / \mathrm{kg} / \mathrm{min}$ ) but the other two had normal postnatal SVC flow. This may relate to the mixed prenatal and postnatal origins of preterm ischaemic white matter injury. ${ }^{31}$

These observations suggest that prevention of IVH and ischaemic cerebral injury would be possible if a rational strategy to maintain systemic blood flow could be developed. These data emphasise the importance of minimising early mean airway pressure and suggest that medical closure of ducts failing to constrict in the first few postnatal hours would help to support the systemic circulation. The latter is probably part of the mechanism by which prophylactic indometacin gives some protection against IVH. ${ }^{32}$ These data would also suggest that afterload reduction, antenatal and postnatal, ${ }^{33}{ }^{34}$ should be explored as a means of circulatory support in the preterm newborn. In testing such interventions, measures of flow not pressure must be used as both the entry criteria and as the outcome variable. To prevent injury to any organ including the brain, it is the volume of blood that is flowing through that organ that must be improved not just the pressure at which that blood is delivered.

In conclusion, we suggest that the early vulnerability of the very preterm infant to low systemic flow states may be due to an immature myocardium struggling to adapt to a high extrauterine vascular resistance. When this is compounded in the vulnerable early period by high intrathoracic positive pressure and a large shunt of blood out of the systemic circulation through the ductus arteriosus, critically low systemic flow and the potential for injury to vulnerable organs results. These data show association between these low flow states and late IVH and do not prove causation. However, for late IVH, we have shown a strong temporal association and a dose-response relation. These, together with biological plausibility from the animal model, increase the likelihood that this association is causal. We suggest that IVH is one consequence of a much wider problem of possibly prenatal, but certainly early postnatal, systemic hypoperfusion in the preterm infant. The injury sustained is dependent on the maturity of the baby, the degree and duration of the hypoperfusion, and clinical events that occur during the period that perfusion is improving.

1 Ment LR, Stewart WB, Duncan CC, Lambrecht R. Beagle puppy model of intraventricular hemorrhage. 7 Neurosurg puppy model of 1 .

2 Evans N, Kluckow M. Early determinants of right and left ventricular output in ventilated preterm infants. Arch Dis ventricular output in ventilated preterm
Child Fetal Neonatal Ed 1996;74:F88-94.

3 Evans N, Kluckow M. Early ductal shunting and intraventricular haemorrhage in ventilated preterm infants. Arch Dis Child Fetal Neonatal Ed 1996;75:F183-6.

4 Kluckow M, Evans N. Relationship between blood pressure and cardiac output in preterm infants requiring mechanical ventilation. F Pediatr 1996;129:506-12.

5 Evans N, Iyer P. Incompetence of the foramen ovale in preterm infants supported by mechanical ventilation. $\mathcal{F}$ Pediatr 1994;125:786-92

6 Evans N, Iyer P. Assessment of ductus arteriosus shunt in preterm infants supported by mechanical ventilation: effect of interatrial shunting. F Pediatr 1994;125:778-85.

7 Kluckow M, Evans N. Superior vena cava flow in newborn infants: a novel marker of systemic blood flow. Arch Dis Child 2000;82:000-00

8 Drayton MR, Skidmore R. Vasoactivity of the major intracranial arteries in newborn infants. Arch Dis Child 1987;62:236-40.

9 Development of audit measures and guidelines for good practice in the management of neonatal respiratory distress syndrome. Report of a Joint Working Group of the British Association of Perinatal Medicine and the Research Unit of the Royal College of Physicians. Arch Dis Child 1992;67:1221-7.

10 Dhainaut JF, Devaux JY, Monsallier JF, Brunet F, Villemant D, Huyghebaert MF. Mechanisms of decreased left ventricular preload during continuous positive pressure ventilation in ARDS. Chest 1986;90:74-80.

11 Henning RJ. Effects of positive end-expiratory pressure on the right ventricle. F Appl Physiol 1986;61:819-26.

12 Biondi JW, Schulman DS, Soufer R, et al. The effect of incremental positive end-expiratory pressure on right ven- 
tricular hemodynamics and ejection fraction. Anesth Analg 1988;67:144-51.

13 Lee LA, Kimball TR, Daniels SR, Khoury P, Meyer RA. Left ventricular mechanics in the preterm infant and their effect on the measurement of cardiac performance. $\mathcal{F}$ Pediatr 1992;120:114-9.

14 Friedman W, F. Intrinsic physiological properties of the developing heart. Prog Cardiovasc Dis 1972;15:87-111.

15 Takahashi Y, Harada K, Kishkurno S, Arai H, Ishida A, Takada G. Postnatal left ventricular contractility in very low birth weight infants. Pediatr Cardiol 1997;18:112-17.

16 Hawkins J, Van Hare GF, Schmidt KG, Rudolph AM Effects of increasing afterload on left ventricular output in fetal lambs. Circ Res 1989;65:127-34.

17 Walker AM, Hanson MA, Spencer JA, Rodeck CH, eds. Circulatory transitions at birth and the control of the neoCircul circulation. In: Fetus and neonate, physiology and clinical applications: the circulation. Cambridge: Cambridge Cal applications: the circulation.

18 Agata Y, Hiraishi S, Oguchi K, et al. Changes in left ventricular output from fetal to early neonatal life. $\mathcal{F}$ Pediventricular output fron

19 Liedholm H, Wahlin Boll E, Hanson A, Ingemarsson I, Melander A. Transplacental passage and breast milk concentrations of hydralazine. Eur $\mathcal{f}$ Clin Pharmaco 1982;21:417-19.

20 Hartikainen Sorri AL, Heikkinen JE, Koivisto M. Pharmacokinetics of clonidine during pregnancy and nursing. Obstet Gynecol 1987;69:598-600.

21 Lou HC, Skov H, Pedersen H. Low cerebral blood flow: risk factor in the neonate. F Pediatr 1979;95:606-9.

22 Pryds O, Greisen G, Lou H, Friis Hansen B. Heterogeneity of cerebral vasoreactivity in preterm infants supported by mechanical ventilation. 7 Pediatr 1989;115:638-45.

23 Goddard Finegold J, Armstrong D, Zeller RS. Intraventricular hemorrhage, following volume expansion after hypovolemic hypotension in the newborn beagle. I Pediatr 1982;100:796-9.
24 Takashima S, Tanaka K. Microangiography and vascular permeability of the subependymal matrix in the premature infant. Can F Neurol Sci 1978;5:45-50.

25 Lou HC. On the pathogenesis of germinal layer hemorrhage in the neonate. APMIS Suppl 1993;40:97-102.

26 Ment LR, Oh W, Philip AG, et al. Risk factors for early intraventricular hemorrhage in low birth weight infants. $\mathcal{F}$ Pediatr 1992;121:776-83.

27 Shaver DC, Bada HS, Korones SB, Anderson GD, Wong SP, Arheart KL. Early and late intraventricular hemorrhage: the role of obstetric factors. Obstet Gynecol rhage: the role

28 Tyszczuk T, Meek J, Elwell C, Wyatt JS. Cerebral blood flow is independent of mean arterial blood pressure in preterm 1998;102:337-41.

29 Perlman JM, McMenamin JB, Volpe JJ. Fluctuating cerebral blood-flow velocity in respiratory-distress syndrome. Relation to the development of intraventricular hemorrhage. $N$ Engl F Med 1983;309:204-9.

30 Funato $M$, Tamai $\mathrm{H}$, Noma $\mathrm{K}$, et al. Clinical events in association with timing of intraventricular hemorrhage in preterm infants. F Pediatr 1992;121:614-19.

31 Murphy DJ, Squier MV, Hope PL, Sellers S, Johnson A. Clinical associations and time of onset of cerebral white matter damage in very preterm babies. Arch Dis Child Fetal Neonatal Ed 1996;75:F27-32.

32 Ment LR, Oh W, Ehrenkranz RA, et al. Low-dose indomethacin and prevention of intraventricular hemorrhage: a multicenter randomized trial. Pediatrics 1994;93:543-50.

33 Nelson KB, Grether JK. Can magnesium sulfate reduce the risk of cerebral palsy in very low birthweight infants? Pediatrics 1995;95:263-9.

34 Roze JC, Tohier C, Maingueneau C, Lefevre M, Mouzard A. Response to dobutamine and dopamine in the hypotensive very preterm infant. Arch Dis Child 1993;69:59-63. 